Article

\title{
Fare Evasion in Public Transport: Grouping Transantiago Users' Behavior
}

\author{
Felipe González ${ }^{1, *}$, Carolina Busco ${ }^{2}$ and Katheryn Codocedo ${ }^{1}$ \\ 1 Faculty of Engineering and Sciences, Department of Industrial Engineering, Universidad Diego Portales, \\ Vergara 432, Santiago 8320000, Chile; katheryn.codocedo@mail.udp.cl \\ 2 CB Estudios de Organización y Entorno, Camino de la Laguna 15111, Santiago 8320000, Chile; \\ cbusco@cbestudios.cl \\ * Correspondence: felipe.gonzalezr@udp.cl
}

Received: 30 October 2019; Accepted: 18 November 2019; Published: 20 November 2019

check for updates

\begin{abstract}
A survey was conducted in July 2018 on the public bus system in Santiago, Chile, in which 457 users were asked to respond to a list of 42 statements expressing a range of attitudes on different aspects of the problem of fare evasion. The respondents were first categorized according to whether they had been observed paying or not paying the fare, and their responses were then subjected to separate cluster analyses that partitioned the respondents into groups according to their views on each survey statement. The analyses identified four distinguishable types or groups among those who did not pay the fare-radical, strategic, ambivalent, and accidental evaders-and three groups among those who did pay-proud, empathetic, and circumstantial evaders. The distinguishing factors motivating the decision to pay or not to pay the fare were found generally to reflect values and attitudes or ideologies but were also influenced by users' perception of the social acceptability of evasion, the presence of anti-evasion measures, and how "organized" they were in taking care to have a farecard with them when planning to take a bus.
\end{abstract}

Keywords: public transport; fare evasion; cluster analysis; Transantiago; consumer behavior

\section{Introduction}

Fare evasion on public transport systems is a worldwide problem, with multiple negative effects such as revenue losses, service quality reductions, and a deterioration in user perception of safety and security [1-3].

In the Chilean capital of Santiago, the problem is rampant, and containing it is a daily struggle. More than just a simple offence, it has become for many a means of expressing discontent with the level of social inequality [4], for which Chile continues to rank among the worst of all OECD (Organisation for Economic Co-operation and Development) members [5]. This reality reflects the fact that the redistributive effects of the country's tax system have been minimal, a situation that is evident in Santiago's bus system, which is used mainly by people in the lowest income quintiles.

Data from the Directorio de Transporte Público Metropolitano, the city's public transport directorate, indicates that the fare evasion rate over the three-year period 2016-2018 averaged about $28 \%$ of trips, peaking at $34.6 \%$ in 2016 . The result has been significant economic losses for the transit system (approximately $\$ 1$ million USD per year). The financial difficulties this entails have prompted the authorities to come up with improvements in the measures aimed at battling evasion on Santiago's bus network where the problem occurs almost exclusively, even though its fare system is integrated with the city's Metro (evasion on the latter is less than $0.1 \%$ ).

Among the steps that have been taken is the creation of an anti-evasion unit, which developed an evasion reduction plan focused on such actions as more vigorous inspection and pursuit of evaders 
through bigger fines, increased ticket checks and the creation of an evader registry, as recommended by various authors $[3,6-8]$. Unfortunately, none of these measures has had much success in mitigating the problem. All of them are predicated on a cost-benefit analysis approach that has not attempted either to determine the underlying causes of evasion or to identify evader user profiles with a view to adopting approaches that are better focused and more effective.

Demands for public transport access to be considered a social right are supported by the United Nations' sustainable development goals for the year 2030. Goal 9.1, for example, calls for the development of "quality, reliable, sustainable and resilient infrastructure," while Goal 11.2 urges the provision of "safe, affordable, accessible and sustainable transport systems for all." The aim of both objectives is to facilitate equal access to the opportunities offered by society, with emphasis on the most vulnerable groups. In this sense, studying evasion as a social phenomenon should contribute to a deeper appreciation of the social challenges currently facing Chile.

These last observations are the inspiration for the following research question: Are there different public transport user profiles driving the fare evasion phenomenon? To find the answer, the authors of the present study conducted a cluster analysis of the responses gathered from a survey of 457 transit riders. Unlike previous research, however, the analysis was conducted both on those who did and those who did not pay the fare. The result was the identification of four categories of evader users and three categories of non-evader users. By broadening the subject of our study in this manner, our results should lead to a better understanding of the evasion phenomenon and a stronger basis for developing new tools to be used in future anti-evasion campaigns that address the problem holistically rather than taking a narrow cost-benefit approach.

\section{Literature Survey}

An economic model of human behavior proposes that someone can engage in a dishonest act intentionally and consciously by making a trade-off between the expected external benefits and the costs of the dishonest act $[9,10]$. Nevertheless a cost-benefit perspective cannot alone explain fare evasion. Mazar et al. [11] infer that people carry out a dishonest behavior to benefit from it, but at the same time, they wish to keep their positive view of themselves as an honest individual. Daunt and Harris [12] recognized that future misbehavior can indirectly be explained by past experiences, where sociodemographic variables such as gender, are important predictors in determining individuals ethical perceptions.

Most published research has focused on explaining public transport fare evasion in terms of the existing infrastructure and other physical conditions (operating factors, vehicle characteristics, use of ticket barriers, etc.) and determining the best measures for reducing the evasion rate [3,7,13-19].

Few studies, however, have investigated the evasion phenomenon with a view to identifying evader types and the reasons that motivate users to pay or not pay transport fares. Investigations that have looked at this aspect [17,20-25] differ in the methodologies they utilize for taking samples and analyzing the data obtained.

Reddy et al. [2] explain how discreet observation of the entrances and exits of a New York City Subway station identified a number of evasion techniques attributed to different evader types. The seven observed methods for illegally enter the station were crawling under the turnstile, entering right behind another person so that both pass through the turnstile on one rotation, "backcocking" the turnstile (i.e., rotating it backward and slipping through the legs so the mechanism does not register an entry), entering through emergency or exit gates held open by an accomplice already in the fare-paid area, entering through gates opened by exiting users, and entering through a gate that is closed but not locked. The authors do not investigate the motivations of the evaders using these methods or the differences between them, however.

Suquet [24], in an ethnographic study of a bus operator in the French city of Cergy-Pontoise, defined six evader categories as determined by fare inspectors-those who cannot afford the fare, 
gamblers, ideological opponents, dissatisfied users, cheats, and users who do not understand the fare system.

Bucciol et al. [20] used surveys taken on the Reggio Emilia (Italy) bus system to study the demographic characteristics of fare evaders, concluding that the probability of evasion is higher among young men, immigrants, and non-Europeans. They also reported that evaders perceive a higher frequency of ticket inspections than non-evaders.

A similar analysis for the bus system in the Italian city of Cagliari was carried out by Barabino et al. [17], who found that young men under 26 years of age who were students, unemployed, or with little education and few alternatives to buses had the greatest propensity to evade. They also observed high levels of evasion among those who took trips under $15 \mathrm{~min}$, were regular users and were dissatisfied with the service. In a later paper, Salis et al. [25] performed a cluster analysis to identify the different evader types with a view to establishing the determinants of each one and how they differ. Their results segmented evaders into three different groups-chronic (those who always evade), calculated risk (those who usually evade), and accidental (those who rarely evade).

Also using cluster analysis, Delbosc and Currie [22] studied the public transport system in Melbourne, Australia, identifying four types of users who evade fares based on differences in attitudes and behavior-accidental evaders, who recognize that not paying is wrong; evaders who justify their evasion claiming it was not their fault; calculated risk evaders; and chronic evaders.

In a subsequent article, Currie and Delbosc [21] developed two models to explain deliberate and unintentional evasion on Melbourne's transit system. They concluded that the explanatory variables were honesty attributes, the ease of evasion, and permissive attitudes, with some influence also attributed to competence in using the ticketing system.

In Chile, research into fare evasion has centered on explaining the operating or macroeconomic conditions that account for the phenomenon without attempting to identify evader types. Guarda et al. [3] found that evasion rates increase with increases in (i) the number of users boarding or alighting at a given bus door, (ii) the number of users boarding through a rear door, (iii) occupancy levels, and (iv) headways. In Guarda et al. [7], the authors concluded that evasion rates are lower at bus stops near intermodal and Metro stations and those located in higher income areas. Finally, using official data on evasion, Troncoso and de Grange [18] showed that the evasion rate rises two percentage points with a $10 \%$ increase in fares but falls 0.8 percentage points with a $10 \%$ increase in ticket inspections.

\section{Methodology}

The data for the present study was obtained by means of a survey taken between the hours of 09:00 and 18:00 during July 2018 aboard vehicles run by Transantiago, the public bus system in Santiago, Chile. A sample of 457 valid responses were obtained. The questionnaire administered to the respondents contained 61 items distributed as follows:

- 10 items describing the user, including age, employment or activity, class of worker (employee, self-employed, etc.), district of residence, purpose of trip, duration of trip in current vehicle, frequency of bus use (days per week), whether or not transferring to the Metro, whether or not the user has an alternative to the bus.

- 42 statements whose reactions were placed on a four-point Likert scale ordered by level of agreement, with a fifth alternative if the indicator is not applicable. The wording of the statements is given in Appendix A.

- Nine observable variables recorded by the interviewer representing (i) the bus-operator company (concessionaire), route, number of doors, presence of turnstile; and (ii) the user-sex, nationality (Chilean, other), the district of the city they boarded in, and whether or not they evaded the fare upon boarding. 
The survey sample was chosen strategically. Routes known to have the highest and lowest evasion rates were identified, reflecting the intention of the study to obtain profiles of both evaders and non-evaders. The interviewers boarded buses on these routes, observed and recorded the behavior of users (payment or evasion of the fare), and then approached them to administer the remaining survey items. This methodology resulted in an accurate capture of user behavior given that it was based on direct observation.

Of the 457 valid responses, there were 234 from evaders and 223 from non-evaders. A statistical summary of the sample is given in the appendices. This total valid respondents are the $75 \%$ of users approached by pollsters. The users that were not able to respond were those who made short trips, given that the responding time was usually between 10-12 $\mathrm{min}$. In order to facilitate responses, users were given a sheet with possible alternatives, allowing a faster process, which was described by pollsters as easy-going and committed. Finally, as the conduct of evasion was observed and not asked to users, the items were not received as judgment toward evaders, who do not usually hesitate in expressing their willingness to perform this conduct and argue openly on its behalf.

The data collected on the evader and non-evader users was subjected to a cluster analysis that sorted the data into groups within which the observations were as similar as possible and between which they were as different as possible. Although the analysis calculates the groups mathematically, the technique is exploratory [26,27], but we believe it is sufficiently sound for the present purpose of establishing user profiles.

The particular method used in the analysis was k-means clustering, which was implemented in the Rstudio statistical software (Viena, Austria) [28]. The decision variables were the users' responses to the 42 statements in the survey. The sociodemographic characteristics of each of the groups are reported compared using a test of proportion [29] to check whether there were any statistically significant differences within each group (see Appendix B).

\section{Results and Discussion}

\subsection{Classification of the Evaders}

Based on their survey responses, the 234 users in the sample who were observed boarding without paying the fare (hereafter "evaders") were partitioned by the cluster analysis into four groups, as summarized in Table 1. Despite the differences between the groups, the evaders as a whole shared the opinion that the Transantiago buses are not safe and that the service shows little concern for the welfare of users. Complementing this was the perception that the vehicles are not well maintained nor are their interiors kept clean, creating a sense of dissatisfaction among users and their milieu with the service provided.

Table 1. Evader group classification.

\begin{tabular}{|c|c|c|c|c|c|}
\hline & \multicolumn{4}{|c|}{ Group } & \multirow{2}{*}{ Total } \\
\hline & 1 & 2 & 3 & 4 & \\
\hline Number of Evaders & 66 & 64 & 67 & 37 & 234 \\
\hline \% Within Group & $28.21 \%$ & $27.35 \%$ & $28.63 \%$ & $15.81 \%$ & $100 \%$ \\
\hline
\end{tabular}

The evaders generally expressed the view that evasion had become accepted by society and that there were situations in which not paying the fare was justified such as running out of farecard funds. They also insisted that Transantiago fares are too high. As for the anti-evasion measures, they acknowledged that they would be afraid to evade if a ticket inspector was present.

Regarding their sociodemographic characteristics, the evaders exhibited gender differences in that there were proportionally more men than women, except in Group 3, where the opposite was true. Although the majority stated they were employed, the proportion was lower than that for the whole 
sample due to the greater presence of students and/or unemployed persons. Finally, regarding the age characteristic, there were proportionally more young people under 19 years of age in the evader groups than in the whole sample. These findings are similar to those reported by $[17,20]$.

The responses of the evaders in the 4 groups were statistically analyzed to differentiate each group's behavior patterns. More specifically, their respective patterns were detected by analyzing the differences in the means of their responses to the 42 survey statements at a $95 \%$ significance level. The statements that showed significant mean differences are set out in Table 2. Also, for each statement, a boxplot was drawn (see Appendix C) to show each group's response behavior, thus identifying graphically the inter-group differences.

\subsubsection{Group 1-Radical Evaders}

Group 1 were the most radical and homogeneous in their responses, which show little dispersion. As may be observed in Boxplots C2, C3, C5, and C10 (see Appendix C), this group denied that evasion is dishonest, illicit, disrespectful, or irresponsible and stated that their family's values do not influence their behavior on paying fares. Unlike the other groups, radical evaders said they did not agree with the statement that "it is wrong not to pay the bus fare." They claimed that evasion is "a valid form of protest" and do not feel guilty when they evade. For these reasons, we characterize them as "radical" evaders. Members of this group are also the only ones who do not consider that evading is unfair to other users, and it does not bother them when an evader occupies a seat (Boxplot C16).

Radical evaders take no special care to bring their farecard or make sure it has funds if they plan to take the bus. They consider that "in some cases, evading is acceptable" and that more places where farecards can be recharged will not eliminate all justification for not paying the fare. They therefore reject the idea that all users should validate their farecards upon boarding a bus (Boxplot C9) and take the view that it is also not evasion to fail to tap their farecard when boarding a bus after using the Metro (as required by the integrated Metro-bus fare system).

Table 2. ANOVA F-test for evader groups.

\begin{tabular}{|c|c|c|c|c|c|}
\hline Statements & Group 1 & Group 2 & Group 3 & Group 4 & Test $\mathrm{F}$ \\
\hline I take care to bring my farecard if I plan to take the bus. & 1.7 & $3.6^{4}$ & 2.4 & $3.8^{2}$ & 107.05 \\
\hline Evading is disrespectful. & $1.9^{2}$ & $2.1^{1}$ & 2.7 & 3.5 & 80.50 \\
\hline Evading is dishonest. & 1.9 & $2.3^{3}$ & $2.5^{2}$ & 3.5 & 66.44 \\
\hline I take care to have funds on my farecard if I plan to take the bus. & 1.7 & $3.2^{4}$ & 2.2 & $3.4^{2}$ & 65.14 \\
\hline Evasion is irresponsible. & $1.9^{2}$ & $2.2^{1}$ & 2.7 & 3.4 & 54.95 \\
\hline If the fines for evasion were bigger, I would hesitate to evade. & 2.0 & $2.9^{3}$ & $3.0^{2}$ & 3.5 & 54.95 \\
\hline I feel guilty when I evade. & 1.5 & 2.1 & $2.7^{4}$ & $2.8^{3}$ & 43.67 \\
\hline It is wrong not to pay the fare. & 2.2 & $2.9^{3}$ & $2.8^{2}$ & 3.5 & 37.63 \\
\hline All users should tap their farecard upon boarding a bus. & 2.0 & $2.8^{3}$ & $2.7^{2}$ & 3.4 & 36.89 \\
\hline Evading is illicit. & 1.9 & $2.4^{3}$ & $2.4^{2}$ & 3.2 & 34.99 \\
\hline Evading is unfair to the other passengers. & $1.9^{2}$ & $2.1^{1.3}$ & $2.3^{2}$ & 3.1 & 32.43 \\
\hline My family's values influence my behaviour on paying fares. & $1.8^{3}$ & $2.7^{4}$ & $2.0^{1}$ & $3.1^{2}$ & 29.91 \\
\hline $\begin{array}{l}\text { If there were more places where farecards could be recharged, } \\
\text { there would be no justification for evading. }\end{array}$ & $2.2^{3}$ & $2.8^{3}$ & $2.5^{1.2}$ & 3.5 & 26.66 \\
\hline In some cases, evading is acceptable. & 3.5 & $3.1^{3}$ & $2.8^{2.4}$ & $2.2^{3}$ & 26.13 \\
\hline I am afraid of sanctions that might result from evasion & 2.1 & $2.5^{3}$ & $2.9^{2.4}$ & $3.3^{3}$ & 23.17 \\
\hline It bothers me when evaders occupy a seat. & 1.7 & $2.3^{3}$ & $2.3^{2}$ & 2.9 & 21.74 \\
\hline Evasion is a valid form of protest. & $3.4^{2}$ & $3.0^{1.3}$ & $2.7^{2.4}$ & $2.2^{3}$ & 20.76 \\
\hline If I lose my farecard, it is OK to evade. & $3.2^{2}$ & $3.1^{1.3}$ & $2.8^{2}$ & 2.1 & 20.31 \\
\hline Bus frequencies are sufficient for my needs. & $1.8^{2.4}$ & $2.0^{1.4}$ & 2.7 & $2.1^{1.2}$ & 19.91 \\
\hline I am satisfied with this bus's service. & $1.9^{2}$ & $2.2^{1.3}$ & $2.4^{2.4}$ & $2.8^{3}$ & 11.80 \\
\hline Fines are effective in reducing evasion. & $1.9^{2}$ & $2.1^{1.3 .4}$ & $2.4^{2.4}$ & $2.5^{2.3}$ & 9.81 \\
\hline $\begin{array}{l}\text { It is evasion not to tap one's farecard when boarding a bus after } \\
\text { using the Metro. }\end{array}$ & 2.0 & $2.4^{3.4}$ & $2.5^{2}$ & $2.6^{2}$ & 8.82 \\
\hline Turnstiles are effective in reducing evasion. & $2.0^{2.4}$ & $2.3^{1.3 .4}$ & $2.4^{2.4}$ & $2.5^{1.2 .3}$ & 3.75 * \\
\hline
\end{tabular}

* Value not significant at $1 \%$. Note: a value of $\mathrm{x}^{1,2,3}$ or 4 indicates that the mean of group $\mathbf{x}$ is not significantly different from the mean of Group 1, 2, 3, or 4 . 
Finally, radical evaders are not satisfied with the bus service provided by Transantiago and state that the service frequencies are not sufficient for their needs. As for anti-evasion measures, they said that neither turnstiles nor fines would reduce evasion and are not afraid of being fined when they evade. They are the only group claiming that they would not hesitate to evade even if the fines were bigger (Boxplot C6).

With respect to sociodemographic characteristics, radical evaders did not differ from the whole sample. There were more males than females in the group, and members were regular users of the system (5-7 times a week). Although the majority were students, in the whole sample, the proportion was not significantly different.

The radical group openly recognized that they are evaders and do not consider their behavior to be anti-social. On the contrary, they see it as a valid form of protest, which to a certain extent was associated with poor service quality. Thus, their strong convictions on the issue make them immune to any mechanism in the system for discouraging evasion. Their definition of the evasion phenomenon is relatively diffuse in that, for them, it is not a simple question of paying or not paying the fare.

This type of evader resembles de classification stablished by Suquet [24] as ideological opponents and dissatisfied users and shows that cost-benefit measures are not enough to contain evasion, given that is understood as a conduct that expresses something beyond the simple cheating in order to reduce individual expenditure.

\subsubsection{Group 2-Strategic Evaders}

As with radical evaders, in the strategic evader group, there were proportionally more men than women. Unlike the rest of the sample, this group had more workers. In similar fashion to evaders generally, they reject the idea that evasion is dishonest, illicit, disrespectful, or irresponsible. The majority of them said that they did not feel guilty when they evaded, affirming that evading is not unfair to other users and that it does not bother them when an evader occupies a seat (Boxplot C16). Just like Group 1, the majority stated that, in some cases, evading is acceptable, such as losing one's farecard or as a form of protest.

Strategic evaders are like radical evaders in being dissatisfied with the service provided by Transantiago, and almost the entire group feels that service frequencies are not sufficient for their needs (Boxplot C19). The group also believe that neither turnstiles nor fines reduce evasion, are not afraid of being fined when they evade, and do not consider that it is evasion to fail to tap their farecard upon boarding a bus after taking the Metro.

However, they are distinguishable from the radical evader group in that they feel it is wrong not to pay the fare, that their family's values do influence their behavior on paying fares, and that all users should tap their farecards upon boarding.

The main characteristics of this group is that they do take care to bring their farecard and make sure it has funds if they plan to take the bus. As regards methods of reducing evasion, they believe that providing more places where farecards can be recharged would reduce the justification for evading (Boxplot C14) and that users would hesitate to evade if fines were bigger.

To sum up, strategic evaders were less radical than those in Group 1 in that they exhibit values that reduce their tendency to evade and lead them to be critical of evasion. They also displayed a certain hesitancy about not paying in the presence of certain anti-evasion measures. However, although they have the means to pay the fare since they are more "organized" in the sense that they take care to bring their farecards and have funds on them if they plan to take the bus, they do evade in a strategic manner, believing it is wrong to do so but doing it nevertheless. In other words, though they have the means to pay, they will not do so if they can get away with it. Thus, depending on the circumstances they pay on some occasions and not on others. This group may be particularly sensitive to more frequent fare inspections and stronger anti-evasion measures. 


\subsubsection{Group 3-Ambivalent Evaders}

Members of the ambivalent evader group consider fare evasion to be acceptable in some cases, such as losing one's farecard, and take the view that more places to recharge farecards will not eliminate the justification for evading. Unlike Groups 1 and 2, though they did evade, they still recognized that it is wrong not to pay the fare and that failing to pay it is dishonest, disrespectful, and irresponsible. At the same time, however, they believe that evasion is not illicit and is a valid form of protest. This set of attitudes is what explains their classification as "ambivalent evaders."

Another example of this ambivalence is evident in their recognition that they feel guilty when they evade, yet they do not believe they are being unfair to other users, nor does it bother them when an evader occupies a seat. Though they are not afraid of being fined when they evade, they take no special care to bring their fare card or make sure it has funds if they plan to take the bus.

Finally, unlike the other groups in this category, ambivalent evaders said they were satisfied with the service of the bus they were riding and consider that service frequencies are sufficient for their needs (Boxplot C19).

This group also feels that turnstiles and fines do not reduce evasion but did say that this could change if fines were bigger. Although they consider that users should tap their farecard when boarding the bus, they do not think that failing to do so after using the Metro constitutes evasion.

The gender makeup of the ambivalent evaders group differed from the whole sample in that it consisted mostly of women. Their age distribution was younger than the other groups.

In short, this group does not appear to be strongly critical of the transport system, and their values sometimes seem to be at odds with their occasional acts of evasion and lack of care in ensuring their fare card had funds, suggesting they are ambivalent or contradictory.

\subsubsection{Group 4-Accidental Evaders}

Accidental evaders were the only ones in the evader category who disagreed with the statement that "in some cases, evading is acceptable." Their evasion occurred when they accidentally ran out of farecard funds. Since they take care to bring their farecard and have funds on it if they plan to take the bus, they believe that if there were more places to recharge farecards, there would be no justification for evading. This attitude is due to their general view that evasion is dishonest, illicit, disrespectful, and irresponsible, and as with Groups 2 and 3, they consider that it is wrong not to pay the fare. They feel guilty when they evade, given that they think evasion is not only wrong but also unfair to other users.

Like the strategic evaders, they stated that their family's values influence their behavior on paying bus fare. They also consider that all users should tap their cards upon boarding and that not doing so after having taken the Metro also constitutes evasion.

Although agreeing with radical and strategic evaders that service frequencies are not sufficient for their needs, they said they were satisfied with the service of the bus they were riding. As regards the anti-evasion measures, occasional evaders are the only ones who consider that turnstiles and fines help reduce evasion and that they would hesitate to evade if the fines were bigger.

In terms of sociodemographic characteristics, this group differed from the whole sample in that they were mainly workers over the age of 35 who take short trips (less than $20 \mathrm{~min}$ ).

To summarize, members of this group only evade in special cases, displaying beliefs, behaviors, and values that distinguish them from evaders in general. Thus, they are classified as accidental evaders. Since they are always willing to pay the fare, what is required to ensure they do is not strong anti-evasion measures but rather more places to charge farecards or, if they did not bring their farecard, other modes of payment.

\subsection{Classification of the Non-Evaders}

The 223 survey respondents in the sample who were observed to have paid the fare (hereafter "non-evaders") were partitioned by the cluster analysis into three groups as shown in Table 3. The data 
indicate that the three have certain characteristics in common, such as considering that not tapping one's farecard upon boarding a bus after using the Metro is evasion, and stating that they always take care to bring their farecard and maintain funds on it when planning to take a bus. Thus, they believe that if there were more places for recharging farecards, there would be no justification for not paying the fare. Although they think fines do not reduce evasion, they also say that they personally would hesitate to evade if the fines were bigger.

Table 3. Non-evader group classification.

\begin{tabular}{ccccc}
\hline & \multicolumn{3}{c}{ Group } & \multirow{2}{*}{ Total } \\
\cline { 2 - 4 } & $\mathbf{1}$ & $\mathbf{2}$ & $\mathbf{3}$ & \\
\hline Number of Non-Evaders & 80 & 122 & 21 & 223 \\
\hline$\%$ Within Group & $35.87 \%$ & $54.71 \%$ & $9.42 \%$ & $100 \%$ \\
\hline
\end{tabular}

As regards Transantiago's image, non-evaders expressed dissatisfaction with the system and a perceived lack of safety aboard the buses. They stated that the system shows little concern for users' welfare and were of the opinion that the buses are not well maintained nor are their interiors kept clean.

The non-evader group may be characterized by the fact that, although they feel evasion has become generally accepted, they believe the fares to be high, and they are not satisfied with the service, they nevertheless paid the fare when they boarded the bus. All of them declared that their family's values influence their attitudes to paying.

As regards sociodemographic characteristics, there were proportionally more women in this group than in the whole sample. Workers and users over the age of 35 were also present in this group in greater proportion.

The statements for which there were statistically significant differences between the three groups in their response means are summarized in Table 4. The behavior patterns of the groups reflected in these results together with the boxplots in Appendix D are identified and described below.

Table 4. ANOVA F-test for non-evader groups.

\begin{tabular}{lcccc}
\hline \multicolumn{1}{c}{ Statements } & Group 1 & Group 2 & Group 3 & Test F \\
\hline Evading is disrespectful. & 3.8 & 3.1 & 1.9 & 111.21 \\
\hline Evading is unfair to the other passengers. & 3.6 & 2.9 & 2.0 & 57.08 \\
\hline I am satisfied with this bus's service. & 3.0 & $2.3^{3}$ & $2.1^{2}$ & 55.77 \\
\hline I am afraid of sanctions that might $\backslash$ n result from evasion. & 3.4 & 3.0 & 2.2 & 52.52 \\
\hline Evasion is irresponsible. & 3.6 & 3.0 & 2.1 & 51.74 \\
\hline I would be afraid to evade if a ticket inspector was present. & $3.4^{2}$ & $3.2^{1}$ & 2.2 & 51.05 \\
\hline Evasion is an illicit act. & 3.6 & $2.9^{3}$ & $2.3^{2}$ & 50.12 \\
\hline Evading is a dishonest. & 3.7 & 3.2 & 2.3 & 50.08 \\
\hline It bothers me when evaders occupy a seat. & 3.6 & 3.1 & 1.9 & 48.35 \\
\hline In some cases, evading is acceptable. & 1.7 & 2.6 & 3.2 & 44.93 \\
\hline I feel guilty when I evade. & 3.5 & 2.7 & 2.0 & 35.97 \\
\hline Evasion is a valid form of protest. & 1.7 & $2.5^{3}$ & $2.9^{2}$ & 28.61 \\
\hline Evading is acceptable if my card runs out of funds. & 2.1 & 2.6 & 3.1 & 22.65 \\
\hline If I lose my farecard, it is OK to evade. & 1.8 & $2.4^{3}$ & $2.5^{2}$ & 19.00 \\
\hline Turnstiles are effective in reducing evasion. & $2.3^{2.3}$ & $2.5^{1}$ & $1.8^{1}$ & 7.33 \\
\hline Bus frequencies are sufficient for my needs. & $2.5^{2.3}$ & $2.3^{1.3}$ & $2.1^{1.2}$ & $3.23 *$ \\
\hline $\begin{array}{l}* \\
\text { Value not significant at 1\%. Note: a value of } x^{1,2,3} \text { or 4 indicates that the mean of group x is not significantly different }\end{array}$ & & & &
\end{tabular}




\subsubsection{Group 1—Proud Non-Evaders}

The proud non-evader group stated for the most part that they "strongly agree" with such statements as "not paying the fare is wrong" and that evading is dishonest, illicit, disrespectful, and irresponsible (Appendix D, Boxplots D1 and D8). They also indicated their strong agreement with the idea that evasion is unfair to other users and they would feel guilty if they evaded. Furthermore, it bothers them when an evader occupies a seat, and they do not consider it acceptable for users to evade even if they have lost their farecard or it has run out of funds.

As is shown in Boxplot D3, proud non-evaders were satisfied with the service on the bus they were riding and with bus frequencies. Regarding anti-evasion measures, they believe that turnstiles do not reduce evasion and also say they would be afraid not to pay in the presence of a ticket inspector but also due to the fines levied for evasion.

In sociodemographic terms, this group did not differ very much from the whole sample, except in terms of age, the majority of them being over 35 .

Summing up, the values and perceptions of this group regarding public transport are such that they reject evasion under any circumstance, and their opinions in this respect are quite radical. Particularly striking is their view that all anti-evasion measures are effective, except turnstiles.

The interesting aspect of studying this group is that they show how social norms can be much stronger than cost-benefit incentives. Proud non-evaders are willing to pay the bus fare even though they are not satisfied with public transport service, evasion is socially accepted, inspections can be outsmarted, and fine payment can be avoided. In a context were cheating is available and costless, the fulfillment of traditional social expectations can be a powerful tool to promote a conduct. Nevertheless, we cannot expect these social norms to be effective or legitimate to all users. They only motivate a small portion of the population studied.

\subsubsection{Group 2-Empathetic Non-Evaders}

This was the largest non-evader group. In sociodemographic terms, its members were little different from the whole sample, and their attitudes are generally very similar to the proud non-evader group, differing in that empathetic non-evaders do consider it to be "acceptable to evade in some cases," such as running out of farecard funds. However, they do not believe it is acceptable if a user loses their farecard or as a form of protest, even though they admit to being dissatisfied with the service provided by Transantiago and feel that bus frequencies are not sufficient for their needs.

The group also agreed that evading is dishonest, illicit, disrespectful, and irresponsible (Boxplots D5 and D7) and stated that they would feel guilty if they evaded, that evasion is unfair to other users and that it bothers them when evaders occupy a seat.

Regarding anti-evasion measures, this group believes that turnstiles do help reduce evasion and that they would be afraid to evade in the presence of an inspector and also because of the fines levied for evasion (see Boxplot D4).

To summarize, the empathetic non-evaders reject excuses for evading under a range of circumstances but do believe it is acceptable to evade in some cases, such as running out of farecard funds.

\subsubsection{Group 3-Circumstantial Non-Evader}

The attitudes of this group, the smallest among the non-evaders, are the opposite of the proud non-evader group. These users stated that evasion is neither dishonest, illicit, disrespectful, nor irresponsible. Like empathetic non-evaders, they consider that it is generally acceptable to evade, particularly as an act of protest or upon losing one's farecard or running out of funds. Evasion does not make them feel guilty, is not seen by them to be unfair to other users, and it does not bother them if evaders occupy a seat.

Users in this group are not satisfied with Transantiago's service or with bus frequencies. As regards anti-evasion measures, they think that turnstiles do not deter evasion and are afraid neither of evading 
in the presence of inspectors nor of the fines levied. Although they all paid their fare, their behavior seems to be influenced by the specific circumstances of their trip, such as the presence of an inspector either on the bus when they boarded or at the bus stop where they began their trip.

Their sociodemographic characteristics were generally different from those of non-evaders. Proportionally, more of them were men and workers, they were typically between 19 and 35 years of age, and they were regular users of public transport.

Finally, the responses of this group to the 42 survey statements indicated that their opinions are quite similar to the ambivalent evader group, differing only in the fact that the circumstantial non-evaders paid the fare for the trip on the bus where they were surveyed.

\section{Conclusions}

The research question that drove this paper was, Are there different public transport user profiles driving the fare evasion phenomenon? To answer this question, a survey was conducted on the public bus system in Santiago, Chile, of the attitudes of system users to the phenomenon of fare evasion and how their attitudes varied depending on whether they had or had not paid the fare on the bus they were riding. The results obtained for the two user categories (evaders and non-evaders) were subjected to separate cluster analyses that partitioned them into groups according to the responses they gave to a number of statements expressing different views on a range of aspects of the evasion problem.

In general terms, the users surveyed have a negative view of the bus system, stating that they and others in their milieu were dissatisfied with the service provided. They feel the system does not contribute to the welfare of the community and perceive a lack of safety attributable to low levels of vehicle maintenance and cleanliness. For all of these reasons, they conclude that fare evasion has become widely accepted and also believe that the fares are high.

The groups in the evader category were distinguishable by the reasons they gave for their behavior, which displayed widely differing ideologies or attitudes and degrees of personal "organization" as regards carrying a system farecard. Taking care to bring their farecard when planning to take the bus and responses to statements on what evasion says about honesty and respect for other users were the most statistically significant variables explaining the differences between the evader groups. The group denoted radical evaders do not think evasion is wrong and are true to that ideal. The strategic evader group, on the other hand, admits that evasion is not right and takes care to have a farecard with them in case an inspector is present. Those classed as ambivalent evaders contradict their own values, believing it is wrong to evade but not taking care always to carry their farecard. Finally, accidental evaders are riders who usually pay the fare but on occasion (such as in this survey) feel they have to evade.

Accidental evaders and circumstantial non-evaders are similar groups, meaning those who sometimes pay and those who sometimes do not pay the bus fare, according mainly to their level of planification and access to charge farecards. These groups may be compared or related to what Salis et al. [25] define as accidental evaders, denoting those who rarely evade and, in this case, do it because of a structural problem (lack of places to refund) that is experienced by users as an unplanned/accidental, "not my fault," issue. This is probably the easiest group to control by structural measures-in this case, new places to charge farecards and ways to pay for the bus fare.

This research's main objective was to broaden the study of fare evasion, leading to a better understanding of the phenomenon and a stronger basis for developing new tools to be used in future anti-evasion campaigns, addressing the problem holistically rather than taking a narrow cost-benefit approach. According to this goal, our main conclusion is that the behavior of both evaders and non-evaders on the Santiago bus system can be explained by variables reflecting values, attitudes and ideologies, social norms, anti-evasion measures and user satisfaction, as an expression of a social phenomenon. This perspective helps to explain why structural measures such as turnstiles have not succeeded in reducing evasion.

On the other hand, once we are able to identify different groups of users, motivated to payment by a varied set of issues, it is easier to understand why mass publicity campaigns are useless in achieving 
their purpose. Each group has their own understanding of the phenomenon, and the arguments used in public campaigns are rarely relevant to those whose conduct we want to change.

A cost-benefit perspective that understands evasion as a way of reducing short-term expenditure and its solution as an incentive/punishment measure lacks the real understanding of this phenomenon. What needs to be recognized is that evasion has become a valid option from various viewpoints, greatly complicating any attempts to reduce its frequency and the associated costs. One of the most relevant aspects is that the demand for public transport access is being considered a social right that allows social inclusion. This perspective is supported by United Nations' sustainable development goals objectives, where public transport is understood as a service that facilitate equal access to the opportunities offered by society.

Unfortunately, currents events in Chile have shown two important conclusions. First, that avoiding a broader social approach toward evasion may unleash countless social consequences, and second, that problems related to public transport may catalyze several social movements and demands.

Author Contributions: Conceptualization, F.G. and C.B.; methodology, F.G., C.B. and K.C.; software, F.G. and K.C.; validation, F.G., C.B. and K.C.; formal analysis, F.G. and C.B.; investigation, F.G., C.B. and K.C.; data curation, K.C.; writing-original draft preparation, F.G. and K.C.; writing-review and editing, F.G. and C.B.; supervision, F.G.; project administration, F.G.; funding acquisition, F.G. and C.B.

Funding: This research was supported by FONDECYT grant no. 1180617.

Conflicts of Interest: The authors declare no conflict of interest.

\section{Appendix A}

Table A1. 42 Survey statements.

\begin{tabular}{|c|c|}
\hline Id & Statement \\
\hline 1 & I take care to have funds on my farecard if I plan to take the bus. \\
\hline 2 & I take care to bring my farecard if I plan to take the bus. \\
\hline 3 & If the fines for evasion were bigger, I would hesitate to evade. \\
\hline 4 & Transantiago buses are safe. \\
\hline 5 & I am satisfied with this bus's service. \\
\hline 6 & Transantiago shows concern for the welfare of its users. \\
\hline 7 & The experience of being inspected affects my trip negatively. \\
\hline 8 & In some cases evading is acceptable. \\
\hline 9 & $\begin{array}{l}\text { If there were more places where farecards could be recharged, there would be no justification for } \\
\text { evading. }\end{array}$ \\
\hline 10 & I feel guilty when I evade. \\
\hline 11 & Transantiago buses are well maintained. \\
\hline 12 & Turnstiles are effective in reducing evasion. \\
\hline 13 & The bus business only benefits the bus operator companies. \\
\hline 14 & It is evasion not to tap one's farecard when boarding a bus after using the Metro. \\
\hline 15 & All users should tap their farecard upon boarding a bus. \\
\hline 16 & I am satisfied with the Transantiago bus service. \\
\hline 17 & Fines are effective in reducing evasion. \\
\hline 18 & My family's values influence my behavior on paying fares. \\
\hline 19 & Evading is dishonest. \\
\hline 20 & Bus frequencies are sufficient for my needs. \\
\hline
\end{tabular}


Table A1. Cont.

\begin{tabular}{|c|c|}
\hline Id & Statement \\
\hline 21 & Transantiago bus interiors are kept clean. \\
\hline 22 & It bothers me when evaders occupy a seat. \\
\hline 23 & Evading is unfair to the other passengers. \\
\hline 24 & I would be afraid to evade if a ticket inspector was present. \\
\hline 25 & If I lose my farecard, it is OK to evade. \\
\hline 26 & Evasion is a valid form of protest. \\
\hline 27 & I would prefer to have another way to charge my farecard. \\
\hline 28 & Evasion has become generally accepted. \\
\hline 29 & People only evade to save money. \\
\hline 30 & Bus fares are too high for me, given my income. \\
\hline 31 & I am not afraid of being fined when I evade. \\
\hline 32 & Evading is disrespectful. \\
\hline 33 & People I know are satisfied with Transantiago's buses and service. \\
\hline 34 & Evading is acceptable if my card runs out of funds. \\
\hline 35 & Evasion is irresponsible. \\
\hline 36 & The pay zone helps to reduce evasion. \\
\hline 37 & Fares are low. \\
\hline 38 & It is wrong not to pay the fare. \\
\hline 39 & Evasion is an illicit act. \\
\hline 40 & Paying in cash is preferable to the farecard system. \\
\hline 41 & Evasion has become a daily occurrence. \\
\hline 42 & Paying the bus fare is more important than paying for bread. \\
\hline
\end{tabular}

\section{Appendix B}

Table A2. Descriptive summary of the sample.

\begin{tabular}{|c|c|c|c|c|c|c|c|c|c|c|}
\hline \multirow{2}{*}{ Characteristics } & \multicolumn{5}{|c|}{ Evaders } & \multicolumn{4}{|c|}{ Non-Evaders } & \multirow{2}{*}{ Sample } \\
\hline & Group 1 & Group 2 & Group 3 & Group 4 & Total Evaders & Group 1 & Group 2 & Group 3 & Total Non-Evaders & \\
\hline \multicolumn{11}{|c|}{ Gender } \\
\hline Male & $65.2 \% *$ & $62.5 \% *$ & $44.8 \% *$ & $59.5 \%$ & $57.7 \% *$ & $43.8 \%$ & $41.8 \%$ & $52.4 \% *$ & $43.5 \% *$ & $50.8 \%$ \\
\hline Female & $34.8 \% *$ & $37.5 \% *$ & $55.2 \% *$ & $40.5 \%$ & $42.3 \% *$ & $56.3 \%$ & $58.2 \%$ & $47.6 \% *$ & $56.5 \% *$ & $49.2 \%$ \\
\hline Total & $100 \%$ & $100 \%$ & $100 \%$ & $100 \%$ & $100 \%$ & $100 \%$ & $100 \%$ & $100 \%$ & $100 \%$ & $100.0 \%$ \\
\hline \multicolumn{11}{|c|}{ Activity } \\
\hline Employee & $30.3 \% *$ & $48.4 \% *$ & $35.8 \%$ & $59.5 \% *$ & $41.5 \% *$ & $68.8 \%$ & $52.5 \%$ & $71.4 \% *$ & $60.1 \% *$ & $50.5 \%$ \\
\hline Student & $45.5 \% *$ & $28.1 \% *$ & $40.3 \%$ & $24.3 \% *$ & $35.9 \% *$ & $18.8 \%$ & $30.3 \%$ & $23.8 \%$ & $25.6 \% *$ & $30.9 \%$ \\
\hline Unpaid activity & $24.2 \%$ & $23.4 \%$ & $23.9 \%$ & $16.2 \%$ & $22.6 \% *$ & $12.6 \%$ & $17.2 \%$ & $4.8 \% *$ & $14.4 \% *$ & $18.6 \%$ \\
\hline Total & $100 \%$ & $100 \%$ & $100 \%$ & $100 \%$ & $100 \%$ & $100 \%$ & $100 \%$ & $100 \%$ & $100 \%$ & $100 \%$ \\
\hline \multicolumn{11}{|c|}{ District of residence (Santiago) } \\
\hline Central & $1.5 \%$ & $4.7 \%$ & $7.5 \%$ & $8.1 \%$ & $5.1 \%$ & $6.3 \%$ & $6.6 \%$ & $14.3 \% *$ & $7.2 \%$ & $6.1 \%$ \\
\hline North & $6.1 \%$ & $20.3 \% *$ & $11.9 \%$ & $13.5 \%$ & $12.8 \%$ & $10.0 \%$ & $13.9 \%$ & $9.5 \%$ & $12.1 \%$ & $12.5 \%$ \\
\hline East & $7.6 \%$ & $3.1 \%$ & $6.0 \%$ & $0.0 \%$ & $4.7 \%$ & $20.0 \%$ & $17.2 \%$ & $19.0 \%$ & $18.4 \%$ & $11.4 \%$ \\
\hline West & $47.0 \%$ * & $53.1 \% *$ & $35.8 \%$ & $21.6 \% *$ & $41.5 \% *$ & $17.5 \%$ & $34.4 \%$ & $19.0 \%$ * & $26.9 \% *$ & $34.4 \%$ \\
\hline South & $13.6 \%$ & $3.1 \% *$ & $11.9 \%$ & $16.2 \%$ & $10.7 \%$ & $12.5 \%$ & $4.9 \%$ & $14.3 \%$ * & $8.5 \%$ & $9.6 \%$ \\
\hline Southeast & $24.2 \%$ & $15.6 \% *$ & $26.9 \%$ & $40.5 \%$ * & $25.2 \%$ & $33.8 \%$ & $23.0 \%$ & $23.8 \%$ & $26.9 \%$ & $26.0 \%$ \\
\hline Total & $100 \%$ & $100 \%$ & $100 \%$ & $100 \%$ & $100 \%$ & $100 \%$ & $100 \%$ & $100 \%$ & $100 \%$ & $100 \%$ \\
\hline
\end{tabular}


Table A2. Cont.

\begin{tabular}{|c|c|c|c|c|c|c|c|c|c|c|}
\hline \multirow{2}{*}{ Characteristics } & \multicolumn{5}{|c|}{ Evaders } & \multicolumn{4}{|c|}{ Non-Evaders } & \multirow{2}{*}{ Sample } \\
\hline & Group 1 & Group 2 & Group 3 & Group 4 & Total Evaders & Group 1 & Group 2 & Group 3 & Total Non-Evaders & \\
\hline \multicolumn{11}{|c|}{ Length of trip (min) } \\
\hline$<20$ & $36.4 \% *$ & $40.6 \%$ & $23.9 \% *$ & $75.7 \% *$ & $40.2 \%$ & $48.8 \%$ & $36.1 \%$ & $28.6 \% *$ & $39.9 \%$ & $40.0 \%$ \\
\hline $20-40$ & $48.5 \%$ & $54.7 \%$ & $59.7 \% *$ & $18.9 \% *$ & $48.7 \%$ & $32.5 \%$ & $50.0 \%$ & $38.1 \%$ & $42.6 \%$ & $45.7 \%$ \\
\hline$>40$ & $15.2 \%$ & $4.7 \% * *$ & $16.4 \%$ & $5.4 \%$ & $11.1 \%$ & $18.8 \%$ & $13.9 \%$ & $33.3 \% * *$ & $17.5 \%$ & $14.2 \%$ \\
\hline Total & $100 \%$ & $100 \%$ & $100 \%$ & $100 \%$ & $100 \%$ & $100 \%$ & $100 \%$ & $100 \%$ & $100 \%$ & $100 \%$ \\
\hline \multicolumn{11}{|c|}{ Age } \\
\hline$<19$ & $18.2 \%$ & $7.8 \% * *$ & $23.9 \% *$ & $5.4 \% * *$ & $15.0 \%$ * & $2.5 \% *$ & $4.1 \%$ & $4.8 \%$ & $3.6 \% *$ & $9.2 \%$ \\
\hline $19-35$ & $66.7 \%$ & $68.8 \%$ & $52.2 \%^{* *}$ & $56.8 \%$ & $61.5 \%$ & $45 \%$ * & $62.3 \%$ & $85.7 \%$ * & $58.3 \%$ & $60.2 \%$ \\
\hline$>35$ & $15.2 \%$ & $23.4 \%$ & $23.9 \%$ & $37.8 \% *$ & $23.5 \% *$ & $52.5 \% *$ & $33.6 \%$ & $9.5 \% *$ & $38.1 \% *$ & $30.6 \%$ \\
\hline Total & $100 \%$ & $100 \%$ & $100 \%$ & $100 \%$ & $100 \%$ & $100 \%$ & $100 \%$ & $100 \%$ & $100 \%$ & $100 \%$ \\
\hline \multicolumn{11}{|c|}{ Frequency of bus use (days per week) } \\
\hline $1-2$ & $3.0 \%$ & $14.1 \%$ & $7.5 \%$ & $16.2 \%$ & $9.4 \%$ & $11.3 \%$ & $12.3 \%$ & $14.3 \%$ & $12.1 \%$ & $10.9 \%$ \\
\hline $3-4$ & $7.6 \%$ & $17.2 \%$ & $25.4 \% *$ & $5.4 \% * *$ & $15.0 \%$ & $13.8 \%$ & $19.7 \%$ & $4.8 \% *$ & $16.1 \%$ & $15.3 \%$ \\
\hline $5-7$ & $89.4 \% *$ & $68.8 \%$ & $67.2 \%$ ** & $78.4 \%$ & $75.6 \%$ & $75.0 \%$ & $68.0 \%$ & $81 . \%^{*}$ & $71.7 \%$ & $73.7 \%$ \\
\hline Total & $100 \%$ & $100 \%$ & $100 \%$ & $100 \%$ & $100 \%$ & $100 \%$ & $100 \%$ & $100 \%$ & $100 \%$ & $100 \%$ \\
\hline
\end{tabular}

* Proportion significantly different from whole sample at $95 \%$ confidence level. ${ }^{* *}$ Proportion significantly different from whole sample at $90 \%$ confidence level.

\section{Appendix C Non-Evaders Boxplot}
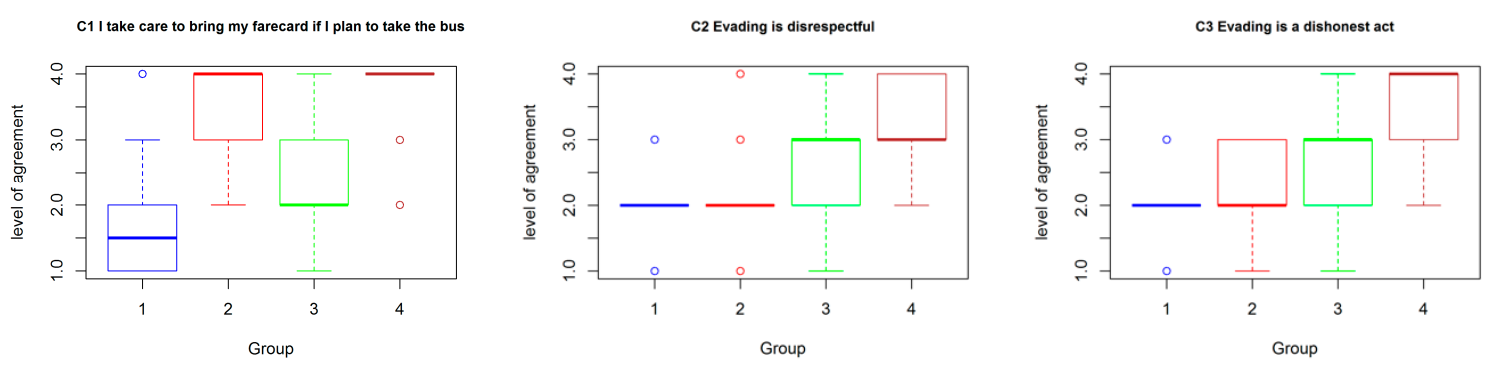

Figure A1. Cont. 

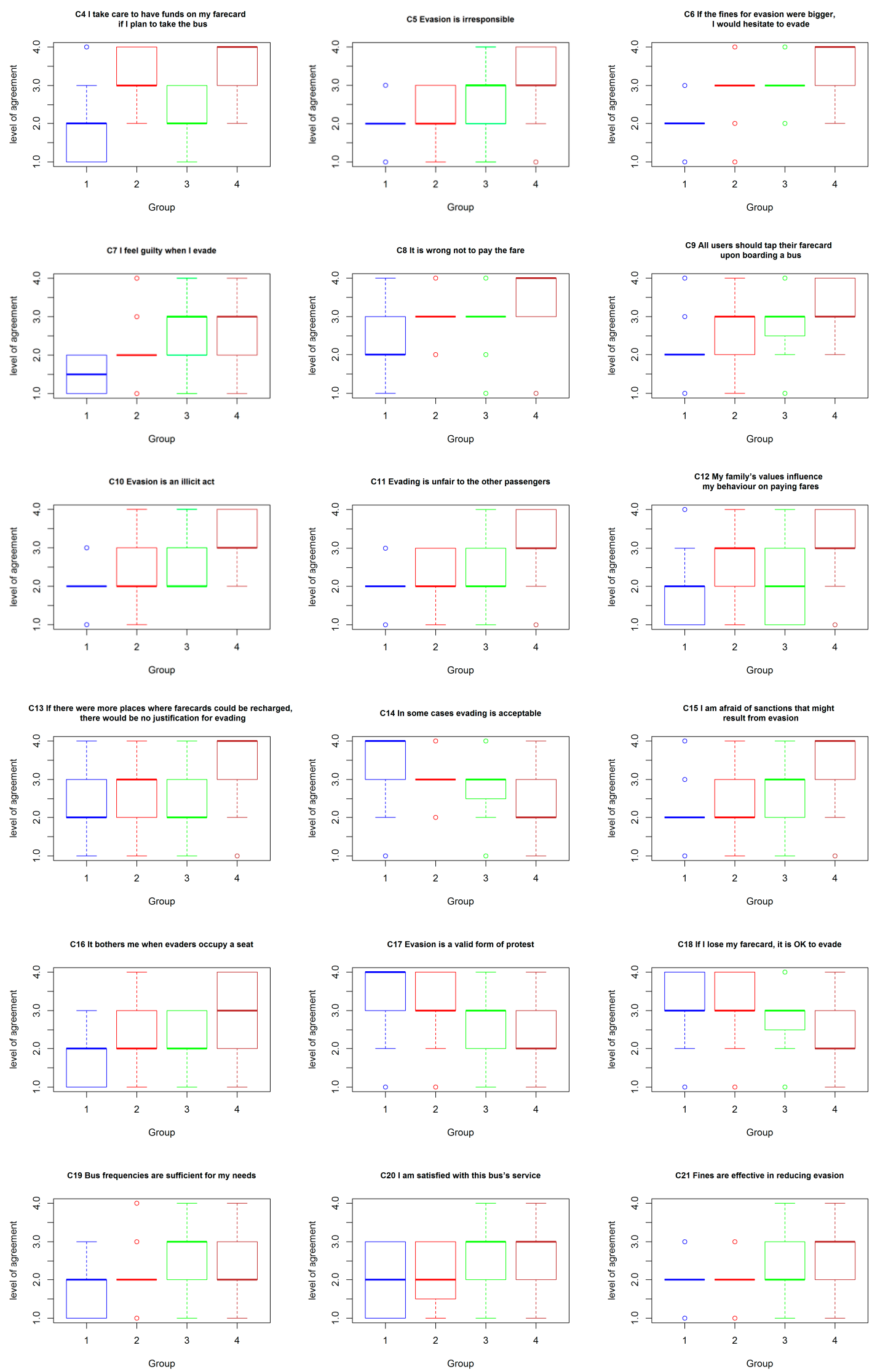

Figure A1. Evaders Boxplot. 

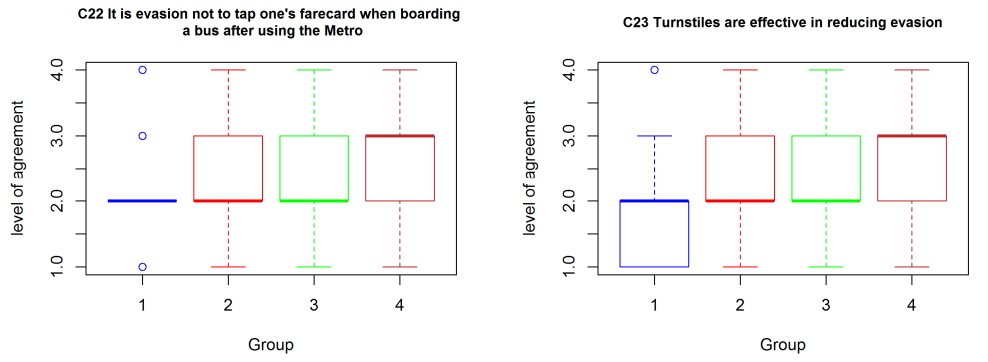

Figure A1. Evaders Boxplot.

\section{Appendix D Non-Evaders Boxplot}
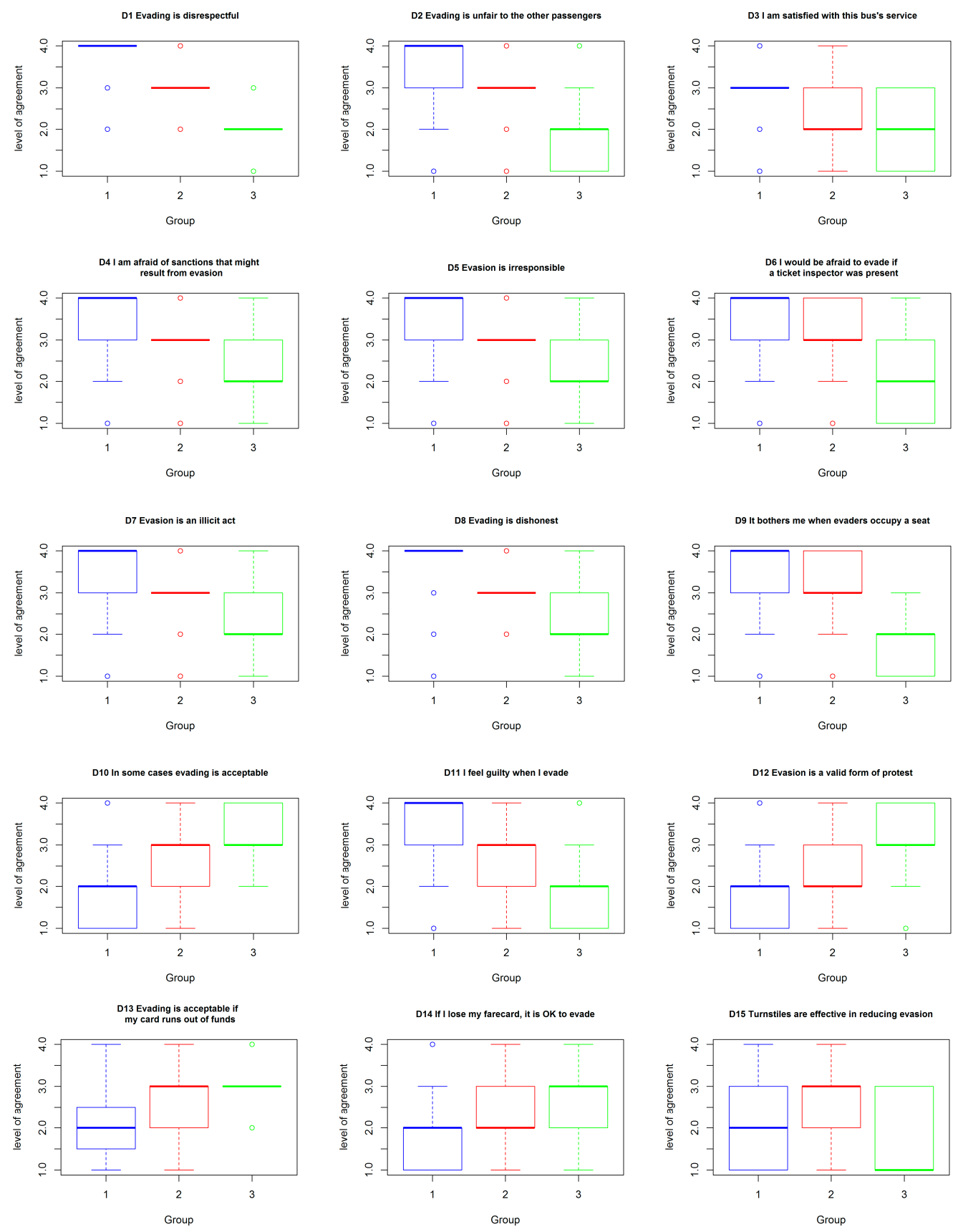

Figure A2. Non-Evaders Boxplot. 


\section{References}

1. Bonfanti, G.; Wagenknecht, T. Human Factors Reduce Aggression and Fare Evasion. Public Transp. Int. 2010, $59,28-32$.

2. Reddy, A.; Kuhls, J.; Lu, A. Measuring and Controlling Subway Fare Evasion. Transp. Res. Rec. J. Transp. Res. Board 2011, 2216, 85-99. [CrossRef]

3. Guarda, P.; Galilea, P.; Paget-Seekins, L.; Ortúzar, J.D. What is behind fare evasion in urban bus systems? An econometric approach. Transp. Res. Part A Policy Pract. 2016, 84, 55-71. [CrossRef]

4. Niehaus, M.; Galilea, P.; Hurtubia, R. Accessibility and equity: An approach for wider transport project assessment in Chile. Res. Transp. Econ. 2016, 59, 412-422. [CrossRef]

5. Cohen, G.; Ladaique, M. Drivers of growing income inequalities in OECD and European countries. In Reducing Inequalities; Springer: Berlin/Heidelberg, Germany, 2018; pp. 31-43.

6. Weidner, R.R. Target-hardening at a New York city subway station: Decreased fare evasion-At what price. Crime Prev. Stud. 1996, 6, 117-132.

7. Guarda, P.; Galilea, P.; Handy, S.; de Dios Ortúzar, J. Decreasing fare evasion without fines? A microeconomic analysis. Res. Transp. Econ. 2016, 59, 151-158. [CrossRef]

8. Tirachini, A.; Quiroz, M. Evasión del Pago en Transporte Público: Evidencia Internacional y Lecciones para Santiago; Universidad de Chile: Santiago, Chile, 2016.

9. Becker, G.S. Crime and punishment: An economic approach. In The Economic Dimensions of Crime; Springer: Berlin/Heidelberg, Germany, 1968; pp. 13-68.

10. Allingham, M.G.; Sandmo, A. Income tax evasion: A theoretical analysis. J. Public Econ. 1972, 1, $323-338$. [CrossRef]

11. Mazar, N.; Amir, O.; Ariely, D. The dishonesty of honest people: A theory of self-concept maintenance. J. Mark. Res. 2008, 45, 633-644. [CrossRef]

12. Daunt, K.L.; Harris, L.C. Customers acting badly: Evidence from the hospitality industry. J. Bus. Res. 2011, 64, 1034-1042. [CrossRef]

13. Dauby, L.; Kovacs, Z. Fare Evasion in Light Rail Systems. Transp. Res. E-Circ. 2007, 112, 230-246.

14. Bijleveld, C. Fare dodging and the strong arm of the law an experimental evaluation of two different penalty schemes for fare evasion. J. Exp. Criminol. 2007, 3, 183-199. [CrossRef]

15. Barabino, B.; Salis, S.; Useli, B. A modified model to curb fare evasion and enforce compliance: Empirical evidence and implications. Transp. Res. Part A 2013, 58, 29-39. [CrossRef]

16. Barabino, B.; Salis, S.; Useli, B. Fare evasion in proof-of-payment transit systems: Deriving the optimum inspection level. Transp. Res. Part B 2014, 70,1-17. [CrossRef]

17. Barabino, B.; Salis, S.; Useli, B. What are the determinants in making people free riders in proof-of-payment transit systems? Evidence from Italy. Transp. Res. Part A 2015, 80, 184-196. [CrossRef]

18. Troncoso, R.; de Grange, L. Fare evasion in public transport: A time series approach. Transp. Res. Part A Policy Pract. 2017, 100, 311-318. [CrossRef]

19. Cools, M.; Fabbro, Y.; Bellemans, T. Identification of the determinants of fare evasion. Case Stud. Transp. Policy 2017, 6, 348-352. [CrossRef]

20. Bucciol, A.; Landini, F.; Piovesan, M. Unethical behavior in the field: Demographic characteristics and beliefs of the cheater. J. Econ. Behav. Organ. 2013, 93, 248-257. [CrossRef]

21. Currie, G.; Delbosc, A. An empirical model for the psychology of deliberate and unintentional fare evasion. Transp. Policy 2017, 54, 21-29. [CrossRef]

22. Delbosc, A.; Currie, G. Cluster analysis of fare evasion behaviours in Melbourne, Australia. Transp. Policy 2016, 50, 29-36. [CrossRef]

23. Delbosc, A.; Currie, G. Four types of fare evasion: A qualitative study from Melbourne, Australia. Transp. Res. Part F Traffic Psychol. Behav. 2016, 43, 254-264. [CrossRef]

24. Suquet, J.-B. Drawing the line: How inspectors enact deviant behaviors. J. Serv. Mark. 2010, $24,468-475$. [CrossRef]

25. Salis, S.; Barabino, B.; Useli, B. Segmenting fare evader groups by factor and cluster analysis. In WIT Transactions on The Built Environment; WIT Press: Cambridge, MA, USA, 2017; Volume 176, pp. 503-515.

26. Ward, J.H., Jr. Hierarchical grouping to optimize an objective function. J. Am. Stat. Assoc. 1963, 58, $236-244$. [CrossRef] 
27. Everitt, B.S.; Landau, S.; Leese, M.; Stahl, D. Cluster Analysis; John Wiley \& Sons. Ltd.: New York, NY, USA, 2011.

28. R Core Team. R: A Language and Environment for Statistical Computing; R Foundation for Statistical Computing: Vienna, Austria, 2017; Available online: https//www.R-project.org (accessed on 15 July 2018).

29. Greene, W.H. Econometric Analysis; Pearson Education India: Bengaluru, India, 2003; ISBN 817758684X.

(C) 2019 by the authors. Licensee MDPI, Basel, Switzerland. This article is an open access article distributed under the terms and conditions of the Creative Commons Attribution (CC BY) license (http://creativecommons.org/licenses/by/4.0/). 